\title{
Passing scopes: A right or a privilege?
}

\author{
Lloyd R Sutherland MD FACP FRCPC, Editor-in-Chief
}

$\mathrm{T}$ he Thomson et al editorial in this issue of the Journal (pages 75-79) provides a forum for several different opinions as to who should be allowed to pass an endoscope in Canada. Dr Thomson is to be congratulated for drawing this issue to our attention. I thought we had dealt with it when I was a Program Director and Chair of the Nucleus Committee in the late 1980s, but apparently I was in error. As one might expect, the opinions range between two extremes. For some, endoscopy should only be performed by graduates of the specialty training programs, while those at the other end of the spectrum believe that anyone who can encourage his or her hospital to buy one should be allowed to scope.

It is difficult to find a politician in Canada who does not pay some form of lip service to providing rural Canada with the same benefits as urban areas. This is, of course, impossible. Data suggest that even within cities, patients with chest pain in close proximity to tertiary care have a better prognosis than those at a greater distance. For the purposes of this discussion, I wonder if endoscopy requires certain credentialing standards in regard to training and quality control. For smaller areas, it may be difficult to enforce standards.

Coming from a small town in New Brunswick, I am sympathetic to the principle of equal access to advanced technology, but there are limits. One of the most important issues in the offering of any service is quality assurance. There is no question that, in the academic environment, there is ongoing informal assessment of quality, but how does one insure the same level of quality in a small hospital with only one endoscope?
Endoscopy patients can be divided into two categories: emergency and elective. The problem arises with patients who are in urgent need of endoscopy. For example, a patient with a bleeding ulcer is a challenge to even the most skilled endoscopist in any academic setting, let alone a small community hospital. For the most part, these patients would be better served by evacuation to a tertiary or advanced secondary level facility. On the other hand, for the more elective patients, an argument could be made for more local access. Then again, this may be altered based on the patient's symptoms.

As a practicing gastroenterologist in an academic setting, it was often somewhat embarrassing to inform a patient referred from a rural area that I had to repeat their endoscopy because I did not understand or was not satisfied with the endoscopy performed in the community. How often a double endoscopy occurs is not known to me, but it must be a drain on the fiscal system.

Perhaps technology can assist. Currently, a variety of robotic initiatives offer the promise of allowing skilled individuals to perform remote procedures. The transmission of high-quality images from a variety of sources to an expert is becoming increasingly common. Perhaps the day is not too far when the 'local' endoscopist inserts a scope and manipulates it according to instructions from the supervising endoscopist from another setting.

One thing is sure: this issue is not going to disappear. 


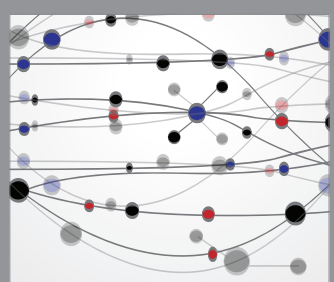

The Scientific World Journal
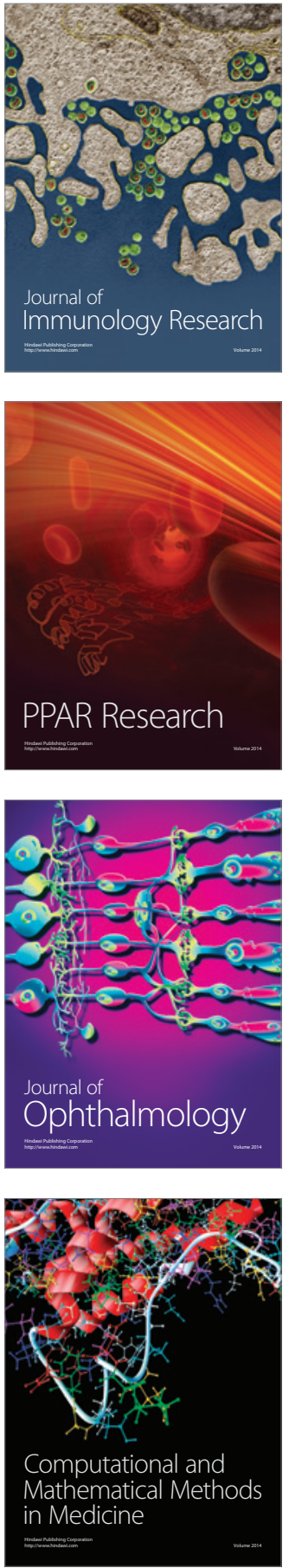

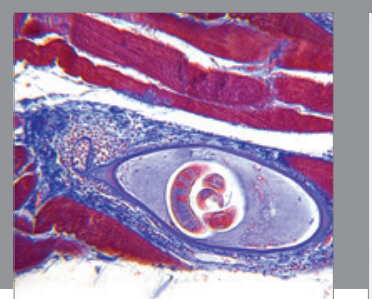

Gastroenterology Research and Practice

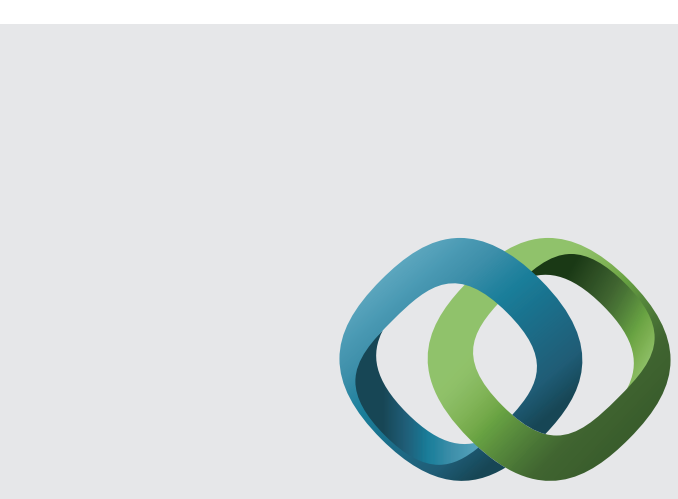

\section{Hindawi}

Submit your manuscripts at

http://www.hindawi.com
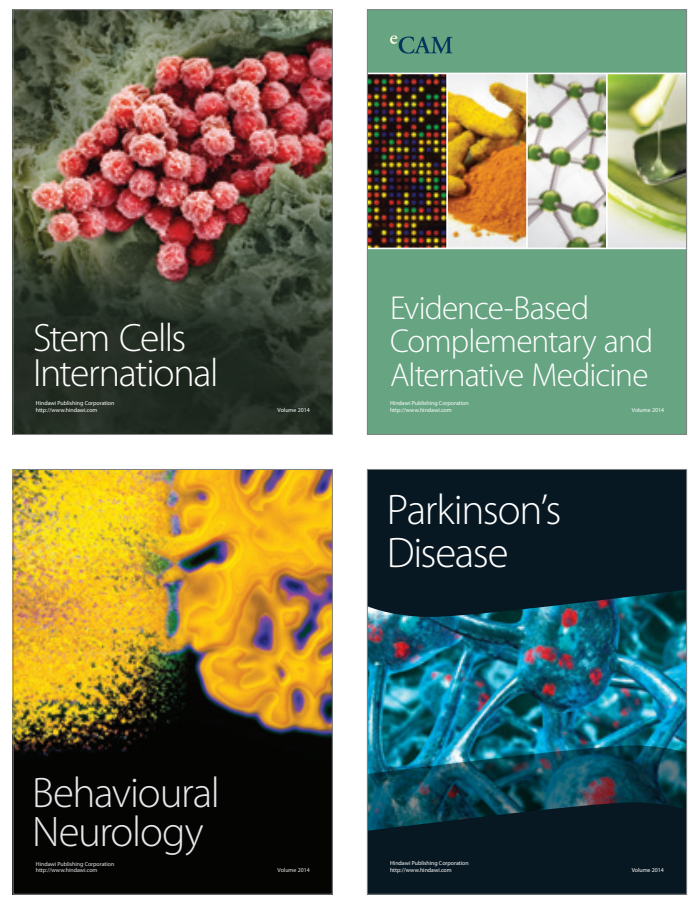
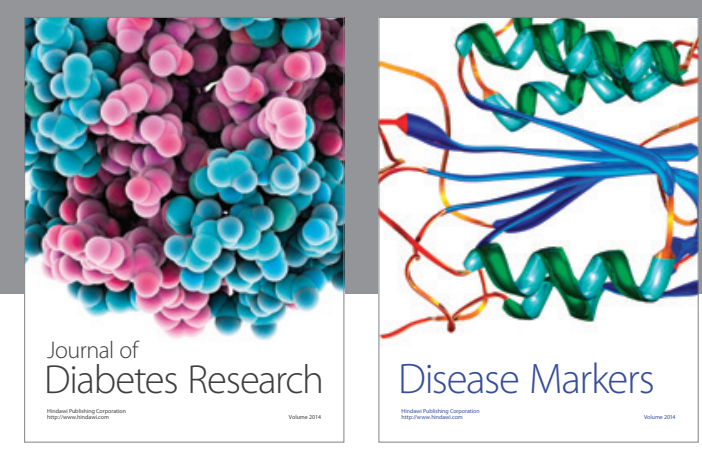

Disease Markers
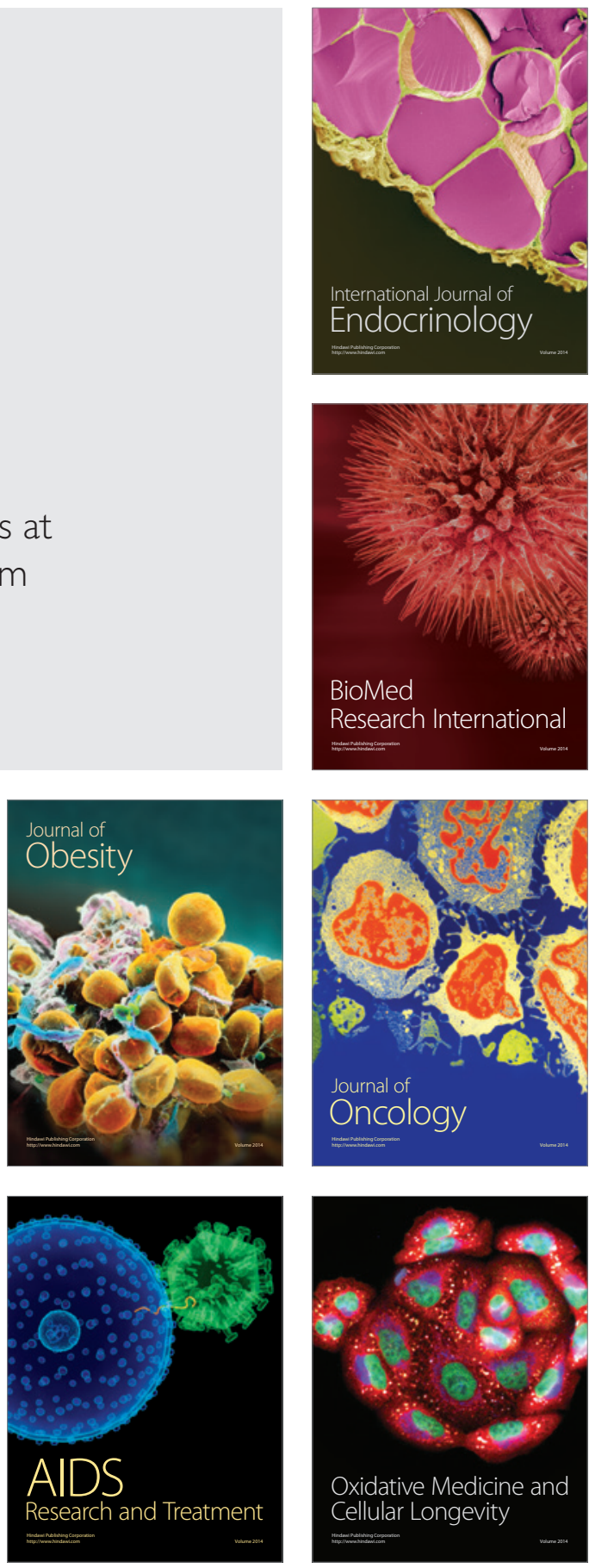